\title{
Soluble uric acid increases PDZK1 and $A B C G 2$ expression in human intestinal cell lines via the TLR4-NLRP3 inflammasome and PI3K/Akt signaling pathway
}

\author{
Mo Chen ${ }^{1,2+}$, Xiaoyong $\mathrm{Lu}^{1+}, \mathrm{Ci} \mathrm{Lu}^{1+}$, Ning Shen ${ }^{3}$, Yujie Jiang ${ }^{1}$, Menglu Chen ${ }^{1}$ and Huaxiang $\mathrm{Wu}^{1 *}$
}

\begin{abstract}
Background: In addition to the kidney, the intestine is one of the most important organs involved in uric acid excretion. However, the mechanism of urate excretion in the intestine remains unclear. Therefore, the relationship between soluble uric acid and the gut excretion in human intestinal cells was explored. The relevant signaling molecules were then also examined.

Methods: HT-29 and Caco-2 cell lines were stimulated with soluble uric acid. Western blotting and GRT-PCR were used to measure protein and mRNA levels. Subcellular fractionation methods and immunofluorescence were used to quantify the proteins in different subcellular compartments. Flow cytometry experiments examined the function of ATP-binding cassette transporter, subfamily G, member 2 (ABCG2). Small interfering RNA transfection was used to assess the interaction between ABCG2 and PDZ domain-containing 1 (PDZK1).

Results: Soluble uric acid increased the expression of PDZK1 and ABCG2. The stimulation of soluble uric acid also facilitated the translocation of $A B C G 2$ from the intracellular compartment to the plasma membrane and increased its transport activity. Moreover, the upregulation of PDZK1 and ABCG2 by soluble uric acid was partially decreased by either TLR4-NLRP3 inflammasome inhibitors or PI3K/Akt signaling inhibitors. Furthermore, PDZK1 knockdown significantly inhibited the expression and transport activity of ABCG2 regardless of the activation by soluble uric acid, demonstrating a pivotal role for PDZK1 in the regulation of ABCG2.
\end{abstract}

Conclusions: These findings suggest that urate upregulates the expression of PDZK1 and ABCG2 for excretion in intestinal cells via activating the TLR4-NLRP3 inflammasome and PI3K/Akt signaling pathway.

Keywords: Hyperuricemia, ABCG2, PDZK1, Intestine

\section{Background}

Pathological hyperuricemia is defined as a serum urate concentration $(408 \mu \mathrm{mol} / \mathrm{L})$ above which monosodium urate (MSU) crystals form at physiological $\mathrm{pH}$ and temperature [1]. Persistent hyperuricemia is widely considered the primary risk factor in several gout-associated diseases, such as gouty arthritis, gouty tophi, and renal damage [2]. An increasing trend in the prevalence of

\footnotetext{
* Correspondence: wuhx8855@zju.edu.cn; wuhx8855@163.com ${ }^{\dagger}$ Equal contributors

'Department of Rheumatology, Second Affiliated Hospital, School of Medicine, Zhejiang University, 310009 Hangzhou, China

Full list of author information is available at the end of the article
}

gout and hyperuricemia has been revealed by epidemiological investigations in several western countries [3, 4]. In Italy, the prevalence of hyperuricemia increased from 85.4 per 1000 inhabitants in 2005 to 119.3 per 1000 inhabitants in 2009 [5]. Therefore, it is crucial to explore the pathophysiological process of hyperuricemia and its effect on target organs.

Underexcretion is the main reason for hyperuricemia in patients with gout [6]. Renal excretion accounts for approximately two-thirds of urate excretion, whereas gut excretion accounts for the rest [2,7]. This process is regulated by a variety of apically and basolaterally expressed reabsorptive and secretory transporters, some 
of which could act as urate-lowering agents [7]. In the gut, the secretory transporter ATP-binding cassette transporter, subfamily G, member 2 (ABCG2) is crucial, and its reduced functioning leads to extra-renal underexcretion, resulting in a compensatory increase in renal urate output [8-11]. Therefore, it is essential to understand the functional and regulatory mechanisms of urate transport that could result in the development of new medications to control urate levels, especially for patients with chronic renal failure.

PDZ domain-containing 1 (PDZK1) is a scaffold protein that binds to several uric acid transporters and mediates their subcellular localization [12-14]. A single-nucleotide polymorphism, rs12129861, in the PDZK1 gene is associated with serum uric acid $[15,16]$. Shimizu et al. [17] reported that the expression of ABCG2 in the intestinal brush-border membranes was reduced in $P d z k 1$-knockout mice, suggesting that PDZK1 is significantly associated with the apical localization of ABCG2.

The clinical features of gout occur as a result of the inflammatory response to MSU crystals [2]. Accumulating evidence has demonstrated that MSU crystalinduced inflammation is a paradigm of innate immunity in gout [18]. Moreover, this inflammatory response is initiated when MSU crystals engaged the caspase-1-activating NOD-like receptor superfamily pyrin domaincontaining 3 (NLRP3) inflammasome, resulting in the production of active interleukin-1 $\beta$ and interleukin-18. [19]. However, hyperuricemia is necessary but not sufficient for gout. Recent findings suggest that the presence of elevated soluble serum uric acid may also exert proinflammatory effects, even in the absence of gout [20-23]. Soluble uric acid increases NLRP3 inflammasome activation in human primary renal proximal tubule epithelial cells [24-26]. However, little is known concerning the effects and molecular mechanisms of uric acid in the intestines.

The aim of this article is to explore the relationship between soluble uric acid and gut excretion as well as the relevant mechanisms. In this study, HT-29 and Caco-2 cells were used as well-established models of human intestinal epithelial cells to examine the human intestinal transport mechanism. The results indicate that soluble uric acid increased the expression of PDZK1 and ABCG2 via the TLR4-NLRP3 inflammasome and phosphatidylinositol-4, 5-bisphosphate 3/kinase (PI3K)/ protein kinase B (Akt) signaling pathway in HT-29 and Caco-2 cells. Stimulation of soluble uric acid also facilitated the translocation of ABCG2 from the intracellular compartment to the plasma membrane and increased its transport activity. An additional study, which was carried out to examine the possible interaction between $P D Z K 1$ and $A B C G 2$, indicated that $P D Z K 1$ plays a pivotal role in the regulation of $A B C G 2$.

\section{Methods}

\section{Reagents and antibodies}

Uric acid, lipopolysaccharide (LPS; from Escherichia coli 0111:B4), Brilliant Blue G, pyrrolidinedithiocarbamate (PTDC), and HEPES were purchased from Sigma-Aldrich (St. Louis, MO, USA). Wortmannin was purchased from MedChemExpress (Monmouth Junction, NJ, USA). Acetyl-YVAD-chloromethylketone and TAK242 were purchased from Calbiochem (Rockland, MA, USA). Pam3CSK4 was purchased from Tocris (Bristol, UK). Antibodies against phosphorylated-Akt (p-Akt), Akt, caspase-1 P10, and caspase-1 P20 were obtained from Cell Signaling Technology (Beverly, MA, USA). Antibodies against ABCG2, PDZK1, Na/K ATPase, Lamin A/C, GAPDH, $\beta$-actin, TLR2, TLR4, MYD88, P2X7, ASC, and nuclear factor $-\kappa B(N F-\kappa B)$ were obtained from Santa Cruz Biotechnology (Santa Cruz, CA, USA). Penicillin/streptomycin and TRIzol reagent were purchased from Invitrogen Life Technologies (Carlsbad, CA, USA).

\section{Cell culture}

HT-29 and Caco-2 human intestinal cell lines were purchased from the Cell Bank of the Chinese Academy of Sciences (Shanghai, China) and cultured in RPMI 1640 and high-glucose Dulbecco's modified Eagle's medium (DMEM) (Invitrogen) containing 10\% fetal bovine serum (FBS; Gibco, Adelaide, Australia). Cells were grown in a humidified incubator containing 5\% $\mathrm{CO}_{2}$ at $37^{\circ} \mathrm{C}$.

During the experiments, a growth arrest period in serum-free medium was observed overnight prior to stimulation. Cells were then treated with uric acid or the solvent $(10 \mathrm{mM} \mathrm{NaOH})$ after the addition of HEPES at a final concentration of $25 \mathrm{mM}$. The solution was filtered through a $0.22-\mu \mathrm{m}$ pore size filter (Millipore, Shanghai, China) before use.

\section{Cellular stimulation conditions}

The inhibitors were dissolved in DMSO or dd $\mathrm{H}_{2} \mathrm{O}$. Cells were pretreated with the corresponding inhibitors in a humidified incubator containing $5 \% \mathrm{CO}_{2}$ at $37{ }^{\circ} \mathrm{C}$ before stimulation with soluble uric acid. The final concentrations and incubation times were as follows: Brilliant Blue G (50 $\mathrm{nM}, 6 \mathrm{~h})$, PTDC (100 $\mu \mathrm{M}, 2 \mathrm{~h})$, Wortmanning $(3 \mu \mathrm{g} / \mathrm{ml}, 2$ h), acetyl-YVAD-chloromethylketone $(20 \mu \mathrm{M}, 2$ h), TAK242 $(2 \mu \mathrm{M}, 2 \mathrm{~h}), \operatorname{Pam} 3 \mathrm{CSK} 4(5 \mu \mathrm{g} / \mathrm{ml}, 2 \mathrm{~h})$, and LPS $(1 \mu \mathrm{g} / \mathrm{ml}, 6 \mathrm{~h})$.

\section{Extraction of subcellular fractions}

For total protein extraction, cells were washed with icecold phosphate-buffered saline (PBS) and lysed in radioimmunoprecipitation assay lysis buffer supplemented with a proteasome inhibitor (Beyotime, Shanghai, China). 
Nuclear and cytoplasmic extractions were prepared using an NE-PER Nuclear Cytoplasmic Extraction Reagent Kit (Pierce, Rockford, IL, USA) according to the manufacturer's instructions. Briefly, cells were washed by suspending the pellet in PBS. Next, ice-cold CER I was added to the cell pellet and vortexed vigorously on the highest setting for $15 \mathrm{~s}$. The tube was then incubated on ice for $10 \mathrm{~min}$. Ice-cold CER II was then added to the tube and vortexed for $5 \mathrm{~s}$ on the highest setting. The tube was incubated on ice for $1 \mathrm{~min}$ and vortexed again. The tube was centrifuged for $5 \mathrm{~min}$ at $16,000 \times g$, and the supernatant (cytoplasmic extract) was immediately transferred to a prechilled tube.

For cell membrane extraction, the Membrane Protein Extraction Kit (BioVision, Inc., Milpitas, CA, USA) was used according to the manufacturer's instructions. In brief, cells were washed with ice-cold PBS and resuspended in Homogenization Buffer Mix in an ice-cold Dounce homogenizer. Cells were homogenized on ice 30-50 times and centrifuged at $700 \times g$ for $10 \mathrm{~min}$ at $4{ }^{\circ} \mathrm{C}$. The supernatant was collected and the pellet discarded. Cells were then centrifuged at $10,000 \times g$ for $30 \mathrm{~min}$ at $4{ }^{\circ} \mathrm{C}$. The pellet represents the cellular membrane protein, whereas the supernatant represents the cytosolic fraction. Membrane proteins were dissolved in $1 \mathrm{M}$ urea.

\section{Western blot analysis}

Equal amounts of protein were separated by $8-12 \%$ sodium dodecyl sulfate polyacrylamide gel electrophoresis and transferred to a polyvinylidene fluoride membrane (Millipore). The membrane was blocked in $5 \%$ nonfat dry milk for $2 \mathrm{~h}$ at room temperature and incubated overnight at $4{ }^{\circ} \mathrm{C}$ with the appropriate primary antibody: GAPDH (1:1000), ABCG2 (1:100), PDZK1 (1:500), MYD88 (1:1000), TLR2 (1:1000), TLR4 (1:1000), ASC (1:1000), NLRP3 (1:2000), caspase-1 P20 (1:1000), caspase-1 P10 (1:2000), P2X7 (1:1000), p-Akt (1:1000), Akt (1:1000), $\beta$-actin (1:1000), NF-kB p65 (1:1000), Na/K ATPase (1:1000), or Lamin A/C (1:1000). Horseradish peroxidase-conjugated goat anti-rabbit or goat antimouse IgG (1:5000; Cell Signaling Technology) was applied as a secondary antibody for $1 \mathrm{~h}$ at room temperature. Membranes were covered with enhanced chemiluminescence solution (Millipore) and exposed to film. Signal intensity was measured using a Bio-Rad XRS chemiluminescence detection system (Bio-Rad, Hercules, CA, USA).

\section{Immunofluorescence}

HT-29 and Caco-2 cells were seeded onto 24-well plates. After treatment, cells were fixed in 4\% paraformaldehyde for $15 \mathrm{~min}$, washed with PBS, and permeabilized with or without $0.1 \%$ Triton X-100 (Beyotime) for $30 \mathrm{~min}$. After blocking in $10 \%$ goat serum for $60 \mathrm{~min}$, slides were incubated with a rabbit ABCG2 antibody (1:40) or a PDZK1 antibody $(1: 100)$ overnight at $4{ }^{\circ} \mathrm{C}$. Samples were then incubated with Alexa Fluor 594-conjugated goat anti-mouse IgG antibody (Invitrogen) for $2 \mathrm{~h}$, and nuclei were stained with 4',6-diamidino-2-phenylindole (DAPI; Sigma-Aldrich). Samples were observed under a fluorescence microscope (Leica, Solms, Germany).

\section{Real-time quantitative polymerase chain reaction}

Total RNA was isolated using TRIzol reagent (Invitrogen) and quantified by measuring the absorbance at $260 \mathrm{~nm}$ (NanoDrop 2000; Thermo Fisher Scientific, Waltham, MA, USA). Complementary single-stranded DNA was synthesized from total RNA by reverse transcription (PrimerScript RT Master Mix; TaKaRa, Kyoto, Japan). Each real-time PCR was performed in a total volume of $20 \mu \mathrm{l}$ in duplicate using the SYBR Premix Ex Taq ${ }^{\text {tix }}$ Kit (TaKaRa) on an ABI StepOnePlus System (Applied Biosystems, Warrington, UK). The following specific primers were used for amplification: GAPDH (forward 5'-AACTCCCACTCTTCCACCTTCG$3^{\prime}$ and reverse 5' ${ }^{\prime}$-TCCACCACCCTGTTGCTGTAG-3'), PDZK1 (forward 5'-CAGCCTCACATTCTTCTT-3' and reverse $5^{\prime}$-GGTCACAACTCATTCCTT-3'), and ABCG2 (forward 5'-AATACATCAGCGGATACTA-3' and reverse 5'-AATAAGCCACCATCATAAG-3'). The cycle conditions were as follows: $95^{\circ} \mathrm{C}$ for $30 \mathrm{~s}$ followed by 40 cycles at $95^{\circ} \mathrm{C}$ for $5 \mathrm{~s}$ and $60{ }^{\circ} \mathrm{C}$ for $30 \mathrm{~s}$. Relative gene expression was analyzed using the $2^{-\Delta \Delta \mathrm{Ct}}$ method.

\section{Flow cytometry}

A detailed protocol for the MDR assay is available in the e-Fluxx-ID ${ }^{\circ}$ Green Multidrug Resistance Assay Kit (ENZO Life Sciences, Inc., Farmingdale, NY, USA) instruction manual. Briefly, on the day of the assay, cells were collected, washed with PBS, and incubated with or without the ABCG2 inhibitor novobiocin in the presence of e-Fluxx-ID Green for $30 \mathrm{~min}$ at $37^{\circ} \mathrm{C}$. Propidium iodide was added to cells during the last $5 \mathrm{~min}$ of incubation and analyzed immediately on a flow cytometer (FACSAriaSORP; BD Diagnostics, Franklin Lakes, NJ, USA) equipped with a blue $(488 \mathrm{~nm})$ laser, and the signals were registered in the FL1/FITC (530/30 filter) channel. Data analysis was performed using FlowJo 8.8.2 software.

To analyze ABCG2 activity, the multidrug resistance factor (MAF) value was calculated using the following formula for each probe:

MAF $=100 \times($ MFI of novobiocin-treated cells-MFI of untreated cells $)$

/MFI of novobiocin-treated cells,

where MFI = mean fluorescence intensity. 


\section{Transfection of human intestinal cells with small interfering RNA}

For small interfering RNA (siRNA) transfection, cells were plated onto six-well plates and cultured in RPMI 1640 or DMEM without FBS and antibiotics overnight before siRNA knockdown. siRNA transfections were carried out using Lipofectamine 2000 (Invitrogen) according to the manufacturer's instructions. Briefly, 10 $\mu \mathrm{l}$ siRNA and $5 \mu \mathrm{l}$ Lipofectamine 2000 reagent were combined in a total of $300 \mu \mathrm{l}$ Opti-MEM I (Gibco, Invitrogen). Thereafter, $700 \mu \mathrm{l}$ Opti-MEM I was added to the mixture, and the mixture was added to each well. After incubation for $6 \mathrm{~h}$, fresh DMEM or RPMI 1640 containing 5\% FBS was added to each well. Cells were returned to the incubator for an additional $48-72 \mathrm{~h}$. The negative control siRNA (scrambled-siRNA) (GenePharma, Shanghai, China) was used to account for nonsequence-specific effects. The siRNA sequences are as follows: ABCG2 siRNA sense:5'-GGAGGCAAAUCUUCGUUAUTT-3' and antisense 5'-AUAACGAAGAUUUGCCUCCTT-3'; and PDZK1 siRNA sense 5'GAUGGAGACAGAGUUCUUATT-3' and antisense: 5'-UAAGAACUCUGUCUCCAUCTT-3'.

\section{Statistical analysis}

Statistical analysis was performed using GraphPad Prism 5.0 software (San Diego, CA, USA). All experiments were performed at least in triplicate, and the data are presented as the mean \pm standard error of the mean (SEM). Statistical significance was determined using one-way analysis of variance followed by Tukey's multiple comparison test when comparing more than two groups. $P \leq 0.05$ was considered to represent a statistically significant difference.

\section{Results}

Expression of PDZK1 and ABCG2 in human intestinal cells is mediated by stimulation of soluble uric acid

Human intestinal cells were exposed to various concentrations of soluble uric acid $(2,4,6$, or $8 \mathrm{mg} / \mathrm{dl})$ or 10 $\mathrm{mM} \mathrm{NaOH}$ for $24 \mathrm{~h}$. The mRNA expression of PDZK1 and ABCG2 increased dramatically after treatment with 6 and $8 \mathrm{mg} / \mathrm{dl}$ soluble uric acid. Real-time quantitative polymerase chain reaction (RT-qPCR) analysis revealed the increases in PDZK1 and ABCG2 mRNA expression respectively in both cell lines compared to control cells (Fig. 1a). Meanwhile, PDZK1 and ABCG2 expression

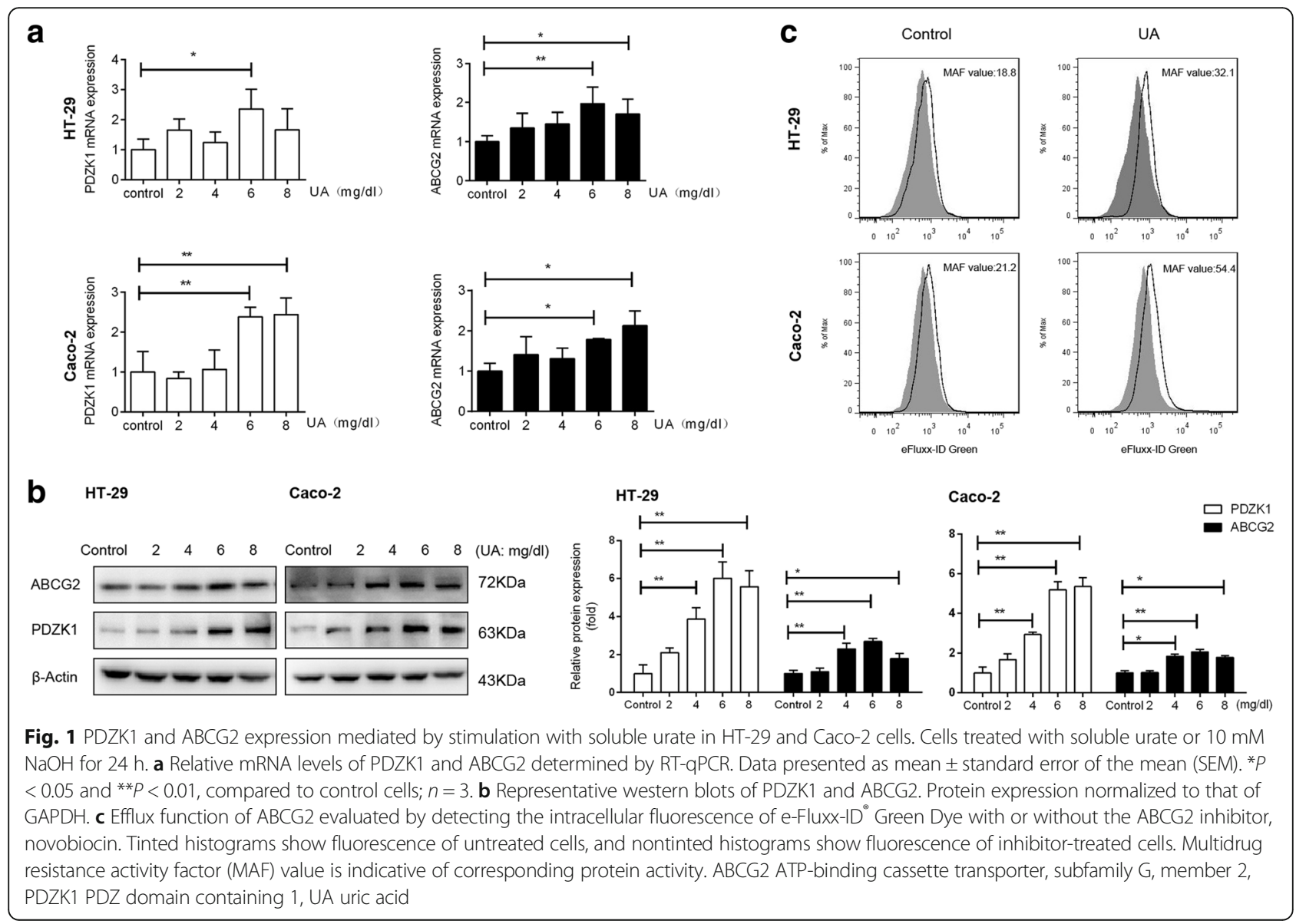


was significantly increased in soluble uric acid-treated cells compared to control cells (Fig. 1b). Cells were also treated with $6 \mathrm{mg} / \mathrm{dl}$ soluble uric acid for 2, 6, 12, 24, 36, or $48 \mathrm{~h}$. The expression of PDZK1 and ABCG2 peaked at $24 \mathrm{~h} \quad(P<0.01$, compared to control cells) (see Additional file 1). Accordingly, this effect was prominent at the concentration of $6 \mathrm{mg} / \mathrm{dl}$ for $24 \mathrm{~h}$ in both HT-29 and Caco-2 cells, and this was used for subsequent experiments.

The function of ABCG2 in HT-29 and Caco-2 cells was examined with e-Fluxx-ID ${ }^{\circ}$ Green Dye with and without a specific inhibitor. Tinted histograms revealed a difference in fluorescence between inhibitor-treated and untreated samples, indicative of ABCG2 protein activity (according to the MAF values). The MAF values revealed weak inhibition on ABCG2 efflux function in both HT-29 and Caco-2 wild-type cells. However, after stimulation with soluble uric acid, the MAF value (32.1) increased significantly, by $70.7 \%$, in HT-29 cells. In Caco-2 cell lines, ABCG2 activity was more than two-fold higher compared to that in wildtype cells (Fig. 1c).

\section{Soluble uric acid altered the subcellular localization of PDZK1 and ABCG2 in human intestinal cells}

To further understand the subcellular distribution of PDZK1 and ABCG2 proteins, we performed immunofluorescence on HT-29 and Caco-2 cells. The ABCG2 signals increased significantly in the membrane after treatment with soluble uric acid. Nevertheless, there were no obvious changes when cells were treated with Triton X-100 (Fig. 2a), probably because ABCG2 protein was present not only in the membrane fractions but also in the cytoplasm. Subcellular fractionation methods were also used to quantify the protein amount in each subcellular compartment. The cytoplasmic fraction was marked by the presence of GAPDH, whereas the membrane fraction contained $\mathrm{Na} / \mathrm{K}$ ATPase, and the nuclear fraction was enriched in nuclear lamina protein Lamin A/C. Western blot analysis demonstrated that soluble

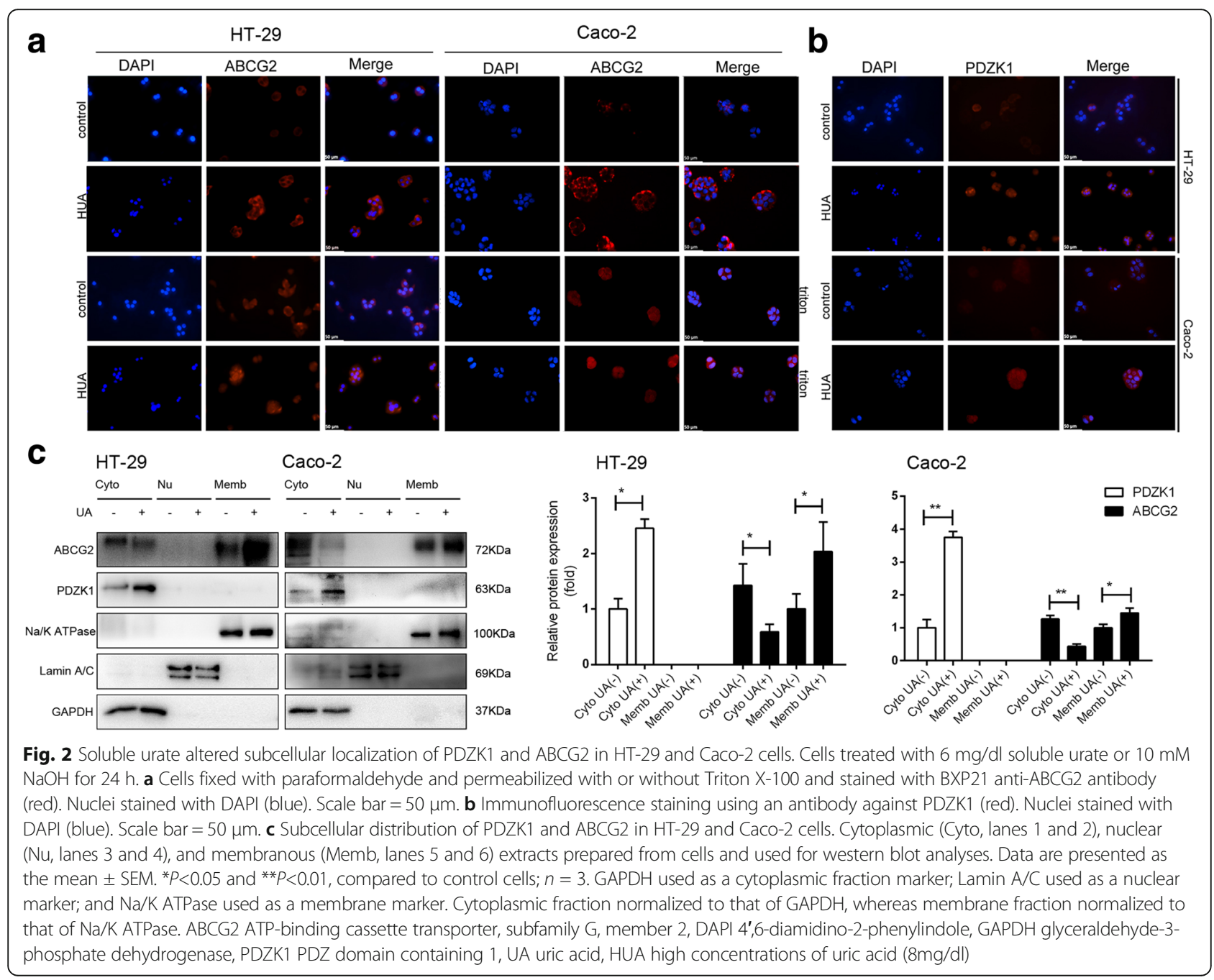


uric acid upregulated the expression of ABCG2 in the membrane fraction and downregulated its expression in the cytoplasm (Fig. 2c). Furthermore, consistent with the immunofluorescence results, ABCG2 protein was not observed in the nucleus (Fig. 2a, c). Together, these findings suggest that soluble uric acid induces the membrane translocation of ABCG2 in HT-29 and Caco2 cells.

Immunofluorescence staining and cell fractionation studies revealed that PDZK1 protein was present in the cytoplasm and exhibited increased expression upon stimulation with soluble uric acid (Fig. 2b, c).

\section{PDZK1 regulated the expression and function of ABCG2 in human intestinal cells}

The results reported indicate the simultaneous regulation of PDZK1 and ABCG2, suggesting their interaction. To address this hypothesis, siRNAs were used to knock down PDZK1 and ABCG2 in HT-29 and Caco-2 cells. Negative control cells were transfected with a scrambled siRNA. PDZK1 and ABCG2 siRNAs strongly attenuated the expression of their corresponding transcripts, as determined by western blot and RT-qPCR analyses; the decreases in expression were statistically significant $(P<$ 0.01, compared to the controls) (Fig. 3a, b). It is also important to note that PDZK1 siRNA reduced ABCG2 expression at both the mRNA and protein levels. In HT-29 and Caco-2 cells, the mRNA expression of ABCG2 was reduced by approximately $50 \%$ after PDZK1 siRNA transfection $(P<0.01$, compared to the control) (Fig. 3a). After transient transfection of ABCG2 siRNA, the mean fluorescence intensity value corresponding to inhibitortreated cells was lower than that of untreated cells (Fig. 3d). In such cases, the corresponding MAF values would be regarded as zero according to the manufacturer's instructions. ABCG2 activity was suppressed by PDZK1 siRNA compared to negative control cells. As shown in Figs. 1c and 3d, the MAF values decreased to $21 \%$ and $33 \%$ in HT-29 and Caco-2 cells, respectively.

Moreover, soluble uric acid failed to increase the expression of ABCG2 after PDZK1 knockdown. The decreases in ABCG2 mRNA expression were $40 \%$ and $66 \%$ in HT-29 and Caco-2 cells respectively. No significant differences were observed in PDZK1-knockdown cells $(P>0.05$, compared to control cells) (Fig. 3a). A significant decrease in ABCG2 protein was observed after PDZK1 siRNA transfection, regardless of the presence of uric acid (Fig. 3b, c). The MAF values of 19.4 and 20.8 increased slightly after treatment with soluble uric acid in PDZK1-knockdown cells. Compared to the uric acid-treated group, the MAF values decreased to $39 \%$ and $62 \%$ respectively (Figs. $1 \mathrm{c}$ and $3 \mathrm{~d}$ ). On the other hand, knockdown of ABCG2 did not affect PDZK1 expression (Fig. 3a, b). Soluble uric acid increased the expression of PDZK1 protein after transient transfection of ABCG2 siRNA relative to soluble uric acid-treated cells (Fig. 3c). The mRNA level did not differ significantly from that of the control group $(P>0.05)$, but was lower than that of the soluble uric acid-treated group $(P<0.01)$ (Fig. 3a).

\section{Soluble uric acid upregulated expression of PDZK1 and ABCG2 by activating the TLR4/NLRP3/caspase- 1 inflammasome}

To investigate the molecular mechanism of the upregulation of PDZK1 and ABCG2 by soluble uric acid, expression of the TLR4/NLRP3/caspase-1 inflammasome was assessed. Soluble uric acid upregulated expression of the NLRP3 inflammasome, which is comprised of NLRP3, apoptosisassociated speck-like protein-containing a CRAD (ASC), and caspase- 1 , indicating that soluble uric acid leads to the production of active caspase-1 (Fig. 4a). We also investigated the proteins located upstream of caspase- 1 in the inflammatory response. Western blot analysis showed no effect on the expression of Toll-like receptor 2 (TLR2) or P2X7, but increases in TLR4 and myeloid differentiation primary response 88 (MYD88) were observed after treatment with soluble uric acid (Fig. 4a, b).

Next, cells were pretreated with the corresponding inhibitors before stimulation. PDZK1 and ABCG2 expression was quantified by RT-qPCR and western blot analyses. Treatment with the caspase-1 inhibitor acetylYVAD-chloromethylketone (Ac-YVAD-CMK, $20 \mu \mathrm{M}$ ) inhibited the increased expression of PDZK1 and ABCG2 induced by soluble uric acid (Fig. 4a, c), whereas the P2X7 inhibitor Brilliant Blue G (50 nM) did not (Fig. 4b, c). Furthermore, the TLR1/2 ligand Pam3CSK4 $(5 \mu \mathrm{g} / \mathrm{ml})$ inhibited the expression of caspase-1, as well as PDZK1 and ABCG2, indicating that active caspase- 1 is relevant in the upregulation of PDZK1 and ABCG2 (Fig. 4a, c). Treatment with TAK-242 $(2 \mu \mathrm{M})$, a small-molecule specific inhibitor of TLR4 signaling, suppressed the soluble uric acid-induced expression of NLRP3, ASC, and caspase-1. Inhibitory effects of PDZK1 and ABCG2 were also observed (Fig. 4a, c). To further explore whether the soluble uric acid-induced increases in PDZK1 and ABCG2 were involved in the TLR4/NLRP3/caspase-1 inflammasome, cells were treated with LPS $(1 \mu \mathrm{g} / \mathrm{ml})$, a potent inducer of the inflammatory response mediated by TLR4. The expression of PDZK1 and ABCG2, as well as of the proteins involved in the TLR4/NLRP3/caspase-1 inflammasome, increased dramatically compared to the control (Fig. 4a, c), suggesting a key role for TLR4.

\section{The soluble uric acid-induced increases in PDZK1 and ABCG2 are partially dependent on PI3K/Akt signaling} Next, we explored whether the soluble uric acid-induced increases in PDZK1 and ABCG2 were associated with the 


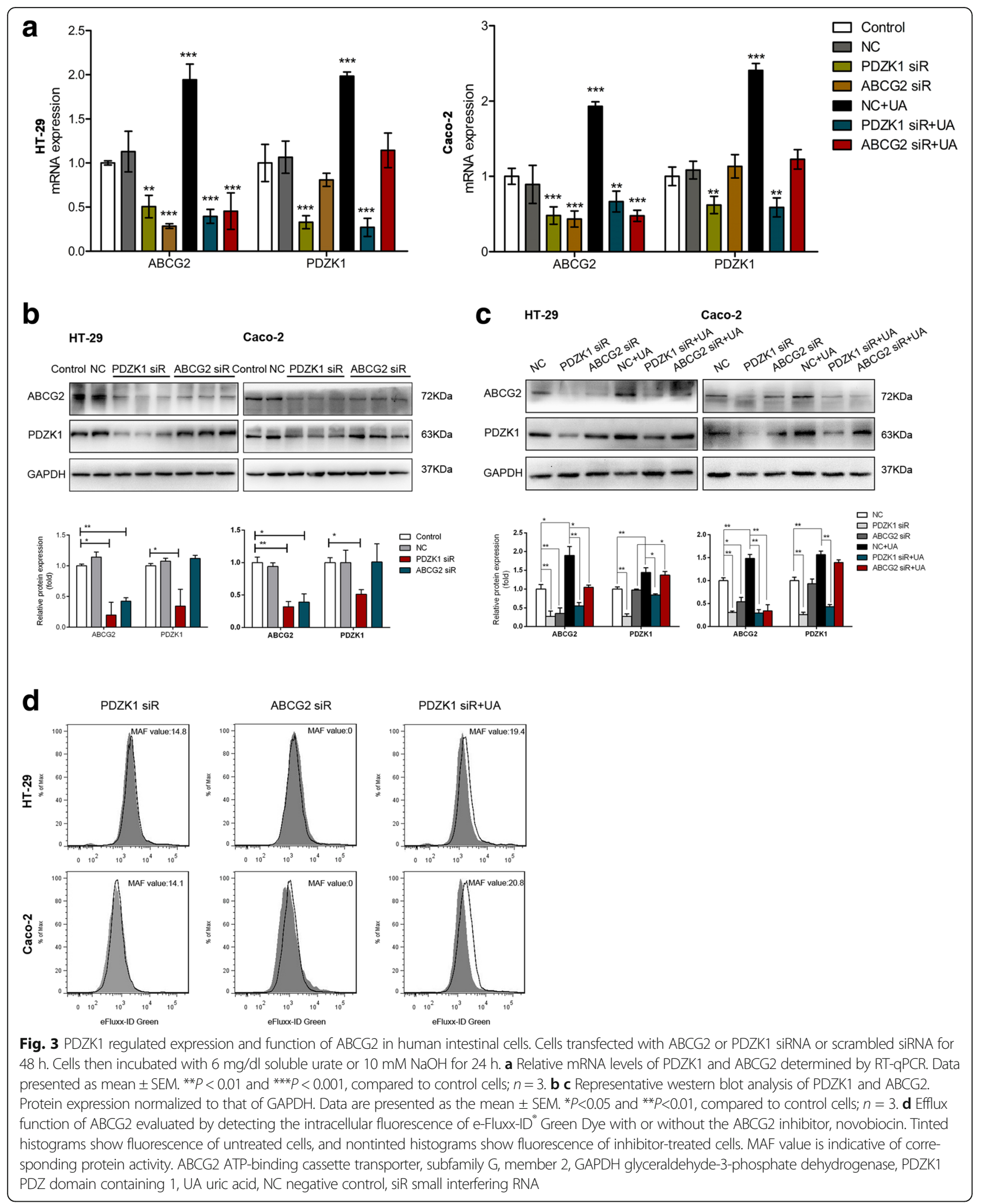

NF-KB or PI3K/Akt signaling pathway. As treatment with soluble uric acid did not modulate the total protein of NFкB p65 (Fig. 5a, b), we used subcellular fractionation to investigate whether p65 translocated from the cytoplasm to the nucleus. Soluble uric acid did not activate the NF$\kappa B$ signaling pathway by classic nuclear translocation of 


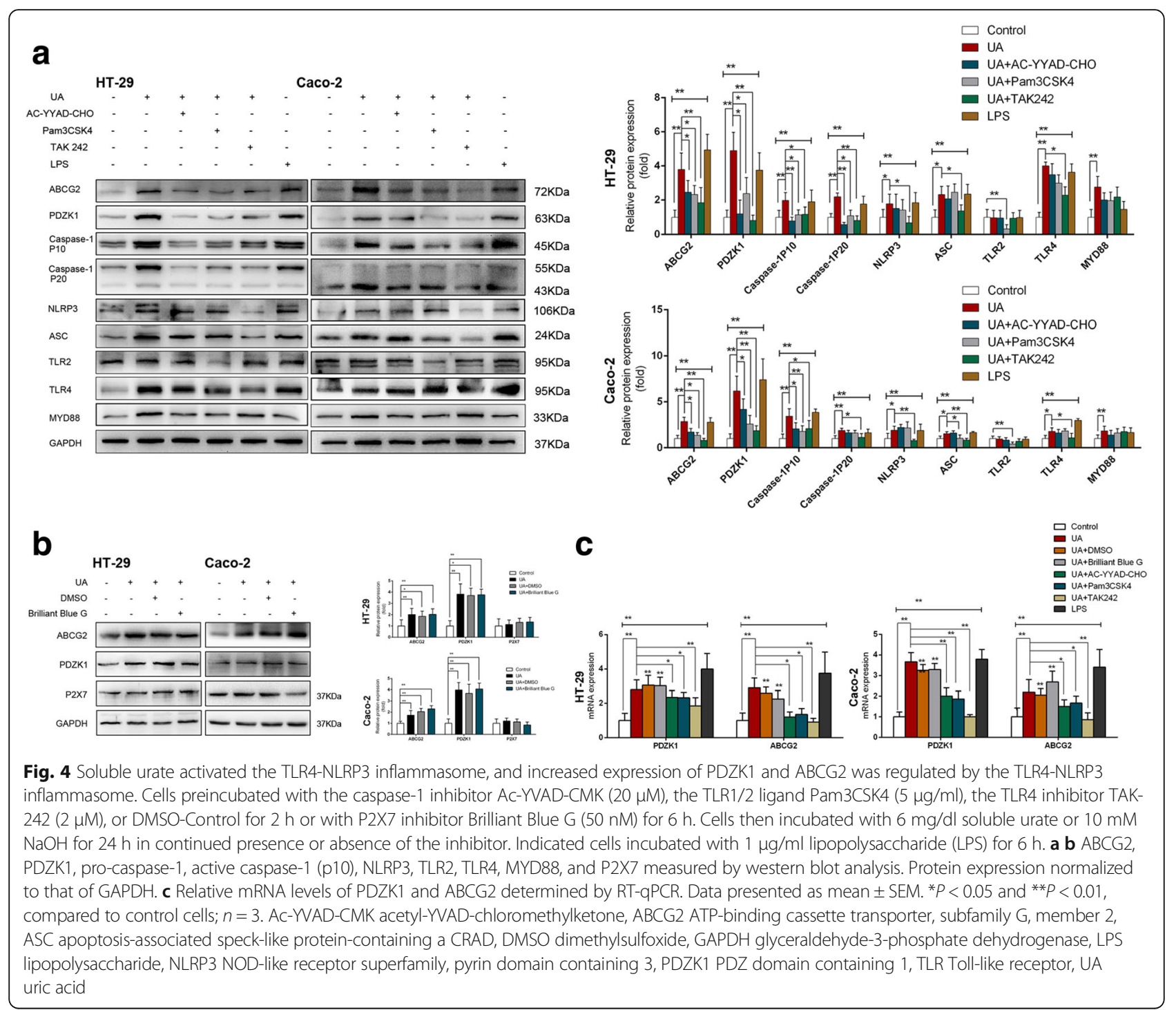

the p65 subunit (Fig. 5c). Meanwhile, the soluble uric acid-induced increases in PDZK1 and ABCG2 expression were not suppressed by the NF- $\mathrm{kB}$ inhibitor, pyrrolidinedithiocarbamate (PTDC, $100 \mu \mathrm{M}$ ) (Fig. 5a, b).

Soluble uric acid activated Akt by phosphorylating Ser473 and Thr450 on in Caco-2 cells and Ser473 in HT-29 cells (Fig. 5d). Moreover, this phosphorylation of Akt was determined to be PI3K-dependent via inhibition with Wortmannin $(2 \mu \mathrm{g} / \mathrm{ml})$. Conversely, inhibition of PI3K by Wortmannin partially reduced the increased expression of PDZK1 and ABCG2 at both the mRNA and protein levels (Fig. 5d, e), suggesting that PI3K/Akt signaling may participate in the soluble uric acidinduced effects.

\section{Discussion}

A previous study demonstrated that soluble uric acid may act as a proinflammatory agent, independent of its precipitated form in MSU crystals [23], providing mechanistic insight into the immunomodulatory properties of soluble uric acid that could be attributed to feedback regulation of urate transporters. Although researchers are becoming increasingly aware that decreased extrarenal urate excretion caused by ABCG2 dysfunction is a common mechanism of hyperuricemia $[8,11,27]$, the effect of soluble uric acid on urate excretion is not completely understood. In this study, we show a relevant link between soluble uric acid and the gut excretion (Fig. 6). And for the first time, we show a mechanism for the upregulation and transport activities of gut urate excretion (Fig. 6).

HT-29 and Caco-2 cells, which are well-established models of human intestinal epithelial cells, were used to examine the human intestinal transport mechanism. ABCG2, a high-capacity urate exporter, facilitates uric acid secretion in the intestine rather than the proximal tubule 


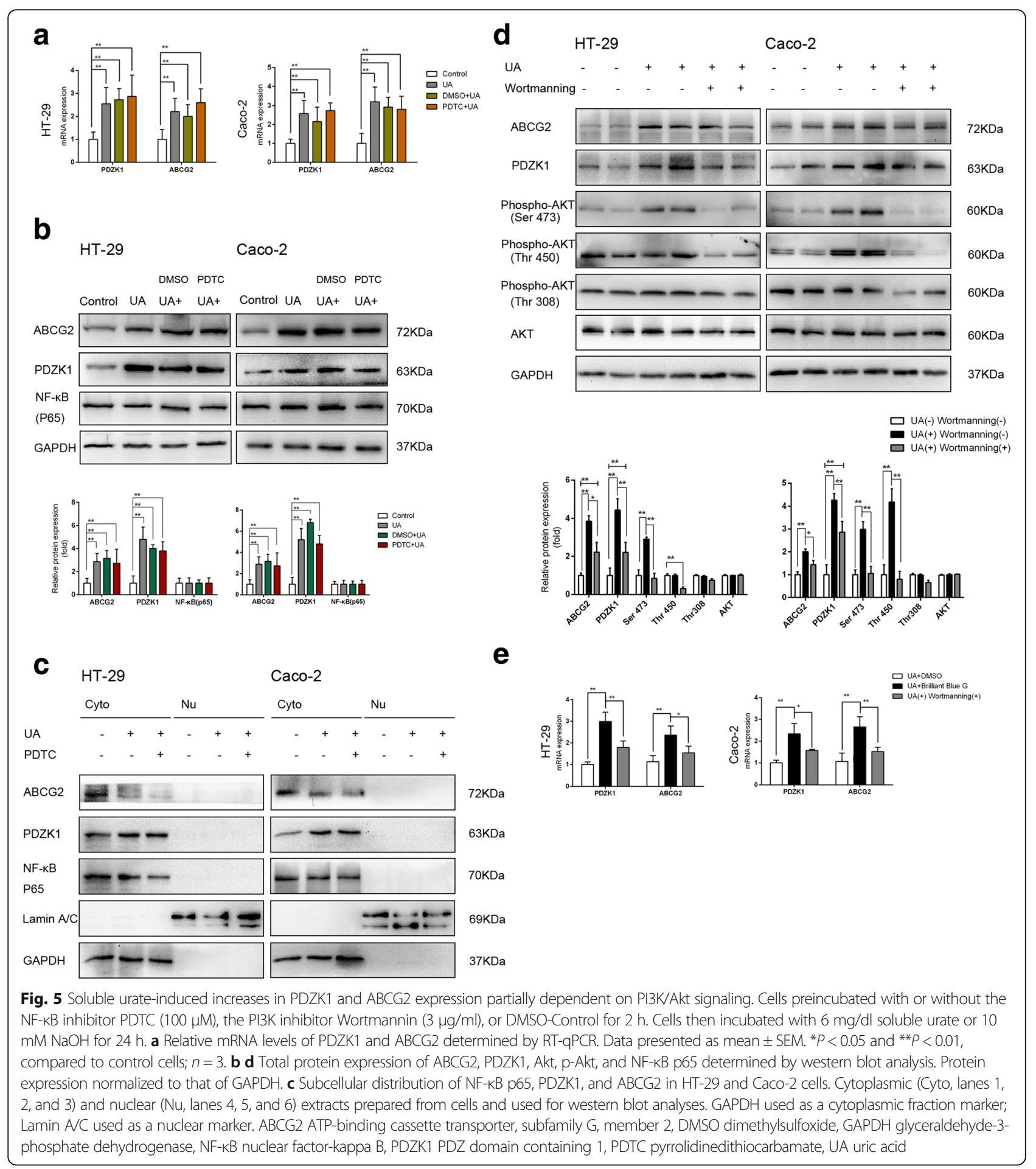

of the kidney [8]. These experiments revealed that soluble uric acid could also attribute to a feedback regulation of the urate transporters in human intestinal cell lines.

Stimulation of soluble uric acid appears to facilitate the translocation of ABCG2 from the intracellular compartment to the plasma membrane, where it mediates renal urate secretion. A more robust transport assay (i.e., using membrane vesicles from HEK293 cells expressing ABCG2) verified its role as a high-capacity urate transporter [28]. Cycling of membrane transporters between the plasma membrane and intracellular sites may serve as a general regulatory paradigm for the expression and activity of transporters at the cell surface [29]. Utilizing this mechanism, the plasma membrane permeability for 


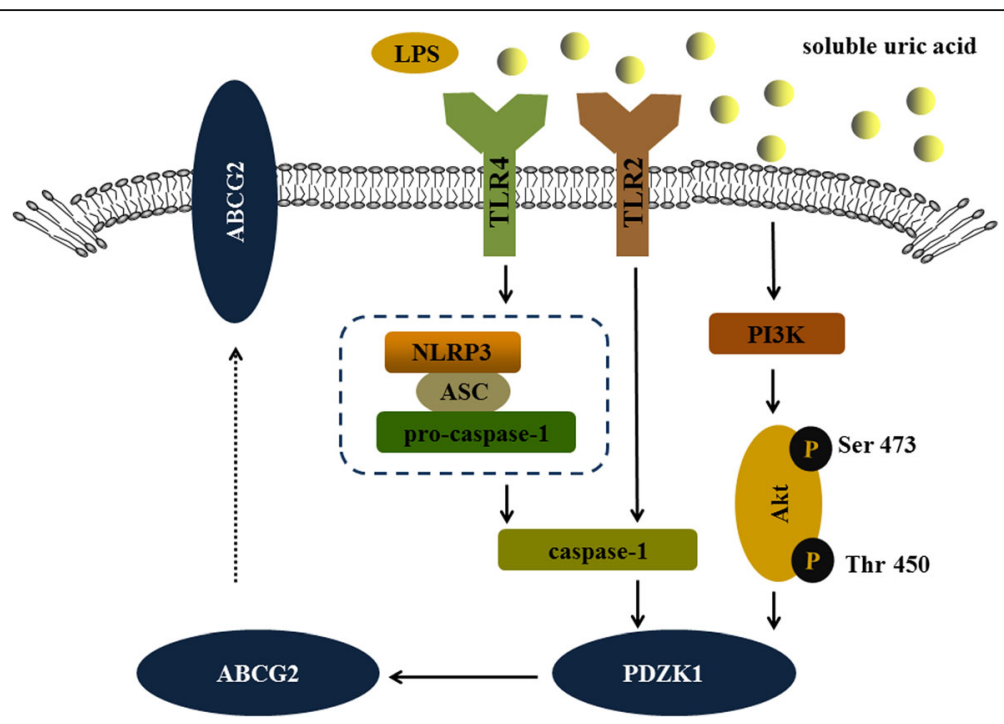

Fig. 6 TLR4-NLRP3 inflammasome and PI3K/Akt signaling pathway modulated expression of PDZK1 and ABCG2 stimulated by soluble uric acid in human intestinal cells. Soluble uric acid interacted with TLR2 or TLR4, initiating the formation of caspase-1 by recruiting the NLRP3 inflammasome, which is comprised of NLRP3, ASC, and pro-caspase-1, and activated the PI3K Akt signaling pathway by phosphorylating Ser473 and Thr450 on Akt. Activation of caspase-1 and Akt increased the expression of PDZK1, which upregulated the expression of ABCG2. ABCG2 ATP-binding cassette transporter, subfamily G, member 2, ASC apoptosis-associated speck-like protein-containing a CRAD, LPS lipopolysaccharide, NLRP3 NOD-like receptor superfamily, pyrin domain containing 3, PDZK1 PDZ domain containing 1, PI3K/Akt phosphatidylinositol-4, 5-bisphosphate 3-kinase/protein kinase B, TLR Toll-like receptor, UA uric acid

certain substances can be rapidly changed to allow cells to respond to varying physiologic conditions [29].

PDZK1 binds to several urate transporters at its PDZ domain, and well-characterized PDZ domain-containing proteins regulate the trafficking and activity of multiple transport proteins in the proximal tubule [13]. In addition to ABCG2, these transport proteins include urate transporter 1 (URAT1/SLC22A12) [30], organic anion transporter 10 (OAT10/SLC22A13) [31], organic anion transporter 4 (OAT4/SLC22A11) [32], and others [15]. Shimizu et al. [17] reported that PDZK1 is a functional regulator and directly interacts with ABCG2 at the protein level. However, there is no evidence that the expression of ABCG2 is affected by the genetic depletion of PDZK1. The present study suggests that this regulation occurs at the transcriptional level in human intestinal cells. Moreover, soluble uric acid failed to increase the expression and function of ABCG2 after knockdown of PDZK1, indicating that increased expression of ABCG2 mediated by uric acid is dependent on PDZK1.

Thus far, major studies investigating the proinflammatory effects of uric acid have focused on MSU crystalinduced inflammation and immunity-related components $[17,22]$. Since uric acid was first considered a signal sensed by innate immunity (including TLR4 activation and NLRP3 inflammasome in gouty arthritis) [25, 26, 33], the role of uric acid metabolism in immune activation and inflammation has become the current direction and hotspot concerning gout. Previous studies examining the role of soluble uric acid have mainly focused on the kidney (both renal tubules [34] and glomerular cells [26]). In the current study, we determined that soluble uric acid activates the TLR4-dependent NLRP3 inflammasome in human intestinal cells. Moreover, the NLRP3 inflammasome plays an important role in the regulation of PDZK1 and ABCG2. However, previous studies have demonstrated decreased expression of PDZK1 in both a mouse model of chronic colitis [35] and in humans with inflammatory bowel disease [36], also suggesting that the regulation of inflammatory mediators is the probable mechanism of PDZK1 expression.

Although increasing evidence has demonstrated that TLRs and MyD88-dependent NF- $\mathrm{kB}$ signaling pathways are both involved in MSU crystal-mediated gouty arthritis [19, 37], soluble uric acid was revealed to have no effect on the NF- $\mathrm{kB}$ signaling pathway in this study.

Canonical TLR signaling by parallel pathways also involves PI3K/Akt in chondrocytes stimulated with MSU and calcium pyrophosphate dehydrate crystals $[19,38]$. Akt, a serine/threonine kinase, is critical for the mediation of cell signaling initiated by growth factors, cytokines, and other cellular stimuli [39]. Inhibition of the PI3K/Akt signaling pathway was recently shown to modulate ABCG2-mediated drug transport via the translocation of ABCG2 from the plasma membrane to intracellular compartments in different cell systems, including side population cells in the bone marrow [40], glioma-derived stem-like cells [41], and ABCG2- 
overexpressing extracellular vesicles derived from MCF7 breast cancer cells [42]. Our findings showed that soluble uric acid activated PI3K/Akt signaling via the phosphorylation of Ser473 and Thr450 on Akt, and its effects on PDZK1 and ABCG2 were modified by the PI3K inhibitor, Wortmannin.

There were several limitations to this study. First, it is possible that the TLR4/NLRP3 inflammasome and the PI3K/Akt signaling pathway interact in response to soluble uric acid. Second, it should be noted that any other mechanisms involved in the inflammatory effects of soluble uric acid cannot be excluded, and this merits further investigation. More importantly, although demonstrated in vitro, these findings should be confirmed in primary intestine cells, as well as in animal models for translational relevance.

\section{Conclusions}

This study set out to investigate the functional and regulatory mechanisms of gut excretion. We show a relevant link between soluble uric acid and the gut excretion. We also show a mechanism for the upregulation of PDZK1 and ABCG2 via the TLR4-NLRP3 inflammasome and PI3K/Akt signaling pathway. Moreover, PDZK1 plays a pivotal role in the regulation of ABCG2. This research will serve as a base for future studies and provide insights for understanding mechanisms of hyperuricemia.

\section{Additional files}

Additional file 1: Figure S1. Human intestinal cells exposed for various times. Cells treated with $6 \mathrm{mg} / \mathrm{dl}$ soluble uric acid for 2, 6, 12, 24, 36, or 48 h. (A) Relative mRNA levels of PDZK1 and ABCG2 determined by RT-qPCR. Data presented as mean \pm standard error of the mean (SEM). ${ }^{*} P<0.05$ and ${ }^{* *} P<0.01$, compared to control cells; $n=3$. (B) Representative western blot assays of PDZK1 and ABCG2 (JPG $435 \mathrm{~kb}$ )

\section{Abbreviations}

ABCG2: ATP-binding cassette transporter, subfamily G, member 2;

ASC: Apoptosis associated speck like protein containing a CRAD; BSA: Bovine serum albumin; DAPI: 4',6-Diamidino-2-phenylindole; DMEM: Dulbecco's modified Eagle's medium; DMSO: Dimethyl sulfoxide;

EDTA: Ethylenediaminetetraacetic acid disodium salt; ELISA: Enzyme-linked immunosorbent assay; FBS: Fetal bovine serum; GAPDH: Glyceraldehyde-3phosphate dehydrogenase; LPS: Lipopolysaccharide; MSU: Monosodium urate; MYD88: Myeloid differentiation factor 8; NF-kB: Nuclear factor-kappa B; NLRP3: NOD-like receptor superfamily, pyrin domain containing 3; P2X7: Purinergic receptor P2X ligand-gated ion channel 7; PBS: Phosphate buffer saline; PCR: Polymerase chain reaction;

PDTC: Pyrrolidinedithiocarbamate; PDZK1: PDZ domain containing 1; PI3K

Akt: Phosphatidylinositol-4, 5-bisphosphate 3-kinase/protein kinase B;

siRNA: small interfering RNA; TLR: Toll-like receptor

\section{Acknowledgments}

Not applicable.

\section{Funding}

This work was supported by National Natural Science Foundation of China (No. 81571577), Zhejiang Provincial Natural Science Foundation of China (No. LY16H100002), and Zhejiang Provincial Public Technology Applied Research Project (No. 2015C33177).

\section{Availability of data and materials}

The data used and/or analyzed during the current study are available from the corresponding author on reasonable request.

\section{Authors' contributions}

MC performed the experiments and was a major contributor to writing the manuscript. XL and HW conceived and designed the study. NS and CL analyzed and interpreted the data. YJ and MC reviewed and edited the manuscript. All authors read and approved the final manuscript.

Ethics approval and consent to participate

Not applicable.

\section{Consent for publication}

Not applicable.

\section{Competing interests}

The authors declare that they have no competing interests.

\section{Publisher's Note}

Springer Nature remains neutral with regard to jurisdictional claims in published maps and institutional affiliations.

\section{Author details}

'Department of Rheumatology, Second Affiliated Hospital, School of Medicine, Zhejiang University, 310009 Hangzhou, China. ${ }^{2}$ Department of Nephrology, Hangzhou Hospital of Traditional Chinese Medicine, 310007 Hangzhou, China. ${ }^{3}$ Department of Rheumatology, Sir Run Run Shaw Hospital, School of Medicine, Zhejiang University, 310009 Hangzhou, China.

Received: 28 July 2017 Accepted: 3 January 2018

Published online: 07 February 2018

\section{References}

1. Loeb JN. The influence of temperature on the solubility of monosodium urate. Arthritis Rheum. 1972;15(2):189-92.

2. Dalbeth N, Merriman TR, Stamp LK. Gout. Lancet. 2016;388(10055):2039-52.

3. Gabriel SE, Michaud K. Epidemiological studies in incidence, prevalence, mortality, and comorbidity of the rheumatic diseases. Arthritis Res Ther. 2009;11(3):229

4. Rho YH, Zhu Y, Choi HK. The epidemiology of uric acid and fructose. Semin Nephrol. 2011;31(5):410-9.

5. Trifiro G, Morabito P, Cavagna L, Ferrajolo C, Pecchioli S, Simonetti M, Bianchini E, Medea G, Cricelli C, Caputi AP, et al. Epidemiology of gout and hyperuricaemia in Italy during the years 2005-2009: a nationwide population-based study. Ann Rheum Dis. 2013;72(5):694-700.

6. Perez-Ruiz F, Calabozo M, Erauskin GG, Ruibal A, Herrero-Beites AM. Renal underexcretion of uric acid is present in patients with apparent high urinary uric acid output. Arthritis Rheum. 2002;47(6):610-3.

7. Mandal AK, Mount DB. The molecular physiology of uric acid homeostasis. Annu Rev Physiol. 2015;77:323-45.

8. Ichida K, Matsuo H, Takada T, Nakayama A, Murakami K, Shimizu T, Yamanashi Y, Kasuga H, Nakashima H, Nakamura T, et al. Decreased extrarenal urate excretion is a common cause of hyperuricemia. Nat Commun. 2012;3:764.

9. Matsuo H, Tsunoda T, Ooyama K, Sakiyama M, Sogo T, Takada T, Nakashima A, Nakayama A, Kawaguchi M, Higashino T, et al. Hyperuricemia in acute gastroenteritis is caused by decreased urate excretion via ABCG2. Sci Rep. 2016:6:31003.

10. Ogura J, Kuwayama K, Sasaki S, Kaneko C, Koizumi T, Yabe K, Tsujimoto T, Takeno R, Takaya A, Kobayashi M, et al. Reactive oxygen species derived from xanthine oxidase interrupt dimerization of breast cancer resistance protein, resulting in suppression of uric acid excretion to the intestinal lumen. Biochem Pharmacol. 2015:97(1):89-98.

11. Nakayama A, Matsuo H, Nakaoka H, Nakamura T, Nakashima H, Takada Y, Oikawa Y, Takada T, Sakiyama M, Shimizu S, et al. Common dysfunctional variants of $A B C G 2$ have stronger impact on hyperuricemia progression than typical environmental risk factors. Sci Rep. 2014;4:5227.

12. Kocher O, Comella N, Tognazzi K, Brown LF. Identification and partial characterization of PDZK1: a novel protein containing PDZ interaction domains. Lab Investig. 1998;78(1):117-25. 
13. Takada Y, Matsuo H, Nakayama A, Sakiyama M, Hishida A, Okada R, Sakurai Y, Shimizu T, Ichida K, Shinomiya N. Common variant of PDZK1, adaptor protein gene of urate transporters, is not associated with gout. J Rheumatol. 2014:41(11):2330-1.

14. Sugiura T, Otake T, Shimizu T, Wakayama T, Silver DL, Utsumi R, Nishimura T, Iseki S, Nakamichi N, Kubo Y, et al. PDZK1 regulates organic anion transporting polypeptide Oatpla in mouse small intestine. Drug Metab Pharmacokinet. 2010;25(6):588-98.

15. Higashino T, Matsuo H, Sakiyama M, Nakayama A, Nakamura T, Takada T, Ogata H, Kawamura Y, Kawaguchi M, Naito M et al. Common variant of PDZ domain containing 1 (PDZK1) gene is associated with gout susceptibility: a replication study and meta-analysis in Japanese population. Drug Metab Pharmacokinet. 2016;31(6):464-66

16. van der Harst P, Bakker SJ, de Boer RA, Wolffenbuttel BH, Johnson T, Caulfield MJ, Navis G. Replication of the five novel loci for uric acid concentrations and potential mediating mechanisms. Hum Mol Genet. 2010;19(2):387-95.

17. Shimizu T, Sugiura T, Wakayama T, Kijima A, Nakamichi N, Iseki S, Silver DL, Kato Y. PDZK1 regulates breast cancer resistance protein in small intestine. Drug Metab Dispos. 2011;39(11):2148-54.

18. Busso N, So A. Mechanisms of inflammation in gout. Arthritis Res Ther. 2010; 12(2):206.

19. Liu-Bryan R, Pritzker K, Firestein GS, Terkeltaub R. TLR2 signaling in chondrocytes drives calcium pyrophosphate dihydrate and monosodium urate crystal-induced nitric oxide generation. J Immunol. 2005;174(8):5016-23.

20. Riteau N, Baron L, Villeret B, Guillou N, Savigny F, Ryffel B, Rassendren F, Le Bert M, Gombault A, Couillin I. ATP release and purinergic signaling: a common pathway for particle-mediated inflammasome activation. Cell Death Dis. 2012;3:e403.

21. Grainger R, McLaughlin RJ, Harrison AA, Harper JL. Hyperuricaemia elevates circulating CCL2 levels and primes monocyte trafficking in subjects with inter-critical gout. Rheumatology. 2013;52(6):1018-21.

22. Ghaemi-Oskouie F, Shi Y. The role of uric acid as an endogenous danger signal in immunity and inflammation. Curr Rheumatol Rep. 2011;13(2):160-6.

23. Crisan TO, Cleophas MC, Oosting M, Lemmers H, Toenhake-Dijkstra H, Netea MG, Jansen $T L$, Joosten LA. Soluble uric acid primes TLR-induced proinflammatory cytokine production by human primary cells via inhibition of IL-1Ra. Ann Rheum Dis. 2016;75(4):755-62.

24. Kim SM, Lee SH, Kim YG, Kim SY, Seo JW, Choi YW, Kim DJ, Jeong KH, Lee TW, Ihm CG, et al. Hyperuricemia-induced NLRP3 activation of macrophages contributes to the progression of diabetic nephropathy. Am J Physiol Renal Physiol. 2015;308(9):F993-F1003.

25. Xiao J, Fu C, Zhang X, Zhu D, Chen W, Lu Y, Ye Z. Soluble monosodium urate, but not its crystal, induces toll like receptor 4-dependent immune activation in renal mesangial cells. Mol Immunol. 2015;66(2):310-8.

26. Xiao J, Zhang XL, Fu C, Han R, Chen W, Lu Y, Ye Z. Soluble uric acid increases NALP3 inflammasome and interleukin-1beta expression in human primary renal proximal tubule epithelial cells through the Toll-like receptor 4-mediated pathway. Int J Mol Med. 2015;35(5):1347-54.

27. Matsuo H, Nakayama A, Sakiyama M, Chiba T, Shimizu S, Kawamura Y, Nakashima H, Nakamura T, Takada Y, Oikawa Y, et al. ABCG2 dysfunction causes hyperuricemia due to both renal urate underexcretion and renal urate overload. Sci Rep. 2014;4:3755.

28. Matsuo H, Takada T, Ichida K, Nakamura T, Nakayama A, Ikebuchi Y, Ito K, Kusanagi Y, Chiba T, Tadokoro S, et al. Common defects of ABCG2, a highcapacity urate exporter, cause gout: a function-based genetic analysis in a Japanese population. Sci Transl Med. 2009;1(5):5ra11.

29. Heukers R, Vermeulen JF, Fereidouni F, Bader AN, Voortman J, Roovers RC, Gerritsen HC, van Bergen En Henegouwen PM. Endocytosis of EGFR requires its kinase activity and $\mathrm{N}$-terminal transmembrane dimerization motif. J Cell Sci. 2013;126(Pt 21):4900-12.

30. Anzai N, Miyazaki H, Noshiro R, Khamdang S, Chairoungdua A, Shin HJ, Enomoto A, Sakamoto S, Hirata T, Tomita K, et al. The multivalent PDZ domaincontaining protein PDZK1 regulates transport activity of renal urate-anion exchanger URAT1 via its C terminus. J Biol Chem. 2004;279(44):45942-50.

31. Miyazaki H, Anzai N, Ekaratanawong S, Sakata T, Shin HJ, Jutabha P, Hirata T, He X, Nonoguchi H, Tomita K, et al. Modulation of renal apical organic anion transporter 4 function by two PDZ domain-containing proteins. Clin J Am Soc Nephrol. 2005;16(12):3498-506.

32. Sakiyama M, Matsuo $H$, Shimizu S, Nakashima H, Nakayama A, Chiba T, Naito M, Takada T, Suzuki H, Hamajima N, et al. A common variant of organic anion transporter 4 (OAT4/SLC22A11) gene is associated with renal underexcretion type gout. Drug Metab Pharmacokinet. 2014;29(2):208-10.

33. Martinon F, Petrilli V, Mayor A, Tardivel A, Tschopp J. Gout-associated uric acid crystals activate the NALP3 inflammasome. Nature. 2006:440(7081):237-41.

34. Ryu ES, Kim MJ, Shin HS, Jang YH, Choi HS, Jo I, Johnson RJ, Kang DH. Uric acid-induced phenotypic transition of renal tubular cells as a novel mechanism of chronic kidney disease. Am J Physiol Renal Physiol. 2013;304(5):F471-80.

35. Lenzen $H$, Lunnemann M, Bleich A, Manns MP, Seidler U, Jorns A. Downregulation of the NHE3-binding PDZ-adaptor protein PDZK1 expression during cytokine-induced inflammation in interleukin-10-deficient mice. PLoS One. 2012;7(7):e40657.

36. Yeruva S, Chodisetti G, Luo M, Chen M, Cinar A, Ludolph L, Lunnemann M, Goldstein J, Singh AK, Riederer B, et al. Evidence for a causal link between adaptor protein PDZK1 downregulation and $\mathrm{Na}(+) / \mathrm{H}(+)$ exchanger NHE3 dysfunction in human and murine colitis. Pflugers Arch. 2015;467(8):1795-807.

37. Zhou R, Yazdi AS, Menu P, Tschopp J. A role for mitochondria in NLRP3 inflammasome activation. Nature. 2011:469(7329):221-5.

38. Hwang HS, Yang CM, Park SJ, Kim HA. Monosodium urate crystal-induced chondrocyte death via autophagic process. Int J Mol Sci. 2015;16(12):29265-77.

39. Manning BD, Cantley LC. AKT/PKB signaling: navigating downstream. Cell. 2007;129(7):1261-74.

40. Aust $\mathrm{S}$, Obrist $P$, Jaeger W, Klimpfinger M, Tucek G, Wrba F, Penner E, Thalhammer T. Subcellular localization of the ABCG2 transporter in normal and malignant human gallbladder epithelium. Lab Investig. 2004;84(8):1024-36.

41. Bleau AM, Hambardzumyan D, Ozawa T, Fomchenko El, Huse JT, Brennan CW, Holland EC. PTEN/PI3K/Akt pathway regulates the side population phenotype and ABCG2 activity in glioma tumor stem-like cells. Cell Stem Cell. 2009;4(3):226-35.

42. To KK, Tomlinson B. Targeting the ABCG2-overexpressing multidrug resistant (MDR) cancer cells by PPARgamma agonists. Br J Pharmacol. 2013; 170(5):1137-51

\section{Submit your next manuscript to BioMed Central and we will help you at every step:}

- We accept pre-submission inquiries

- Our selector tool helps you to find the most relevant journal

- We provide round the clock customer support

- Convenient online submission

- Thorough peer review

- Inclusion in PubMed and all major indexing services

- Maximum visibility for your research

Submit your manuscript at www.biomedcentral.com/submit
Ciomed Central 